\title{
Effect of supplementary videos on scientific reasoning in a general physics course
}

\author{
Amber Sammons, Jessica Tolmie, Rebecca Rosenblatt, and Raymond Zich \\ Department of Physics, Illinois State University, Normal, IL 61790
}

\begin{abstract}
This study investigated the impact of an instructional reform on student scientific reasoning skills and general attitudes toward science. The intervention was administered via eight 5-7 minute videos during lab. Each video consisted of an explanation of its targeted concept, a hands-on demo with observations and YouTube clips highlighting the topic being discussed. While viewing the videos, students were required to answer specific questions testing their comprehension of the concepts and the scientific reasoning being displayed. Lawson's Scientific Reasoning Test was administered to assess improvement in student scientific reasoning skills, and the CLASS was used to assess changes in student attitudes towards science. Pre and Post-test results are compared for a control semester and a semester with this new teaching method. Results show that this video intervention, which took students about two hours in total to complete, significantly improved students' science reasoning skills and their attitudes towards science.
\end{abstract}

\section{INTRODUCTION}

When instructors are asked their instructional goals for general education physics classes there will likely be a lot of comments about science literacy and developing students' basic understanding of important science concepts, such as experimental design and data interpretation [1,2]. The same instructors may also offer comments about the beauty of science or how science applies to peoples' everyday lives. But, while these tend to be goals for a course as a whole, they often get lost in the content of learning Newton's Laws or energy conservation. In fact, several studies have shown that even after taking many physics courses students' science reasoning and science literacy skills are low [2-5]. Also, studies have found that students attitudes toward science often drop over the course of a semester taking physics [6].

The effects of an instructional modification designed to improve students' scientific reasoning skills and attitudes toward science through a general education physics course are presented here. The instructional modification was tailored to the needs of the course as a whole. Ideally, a set of hands-on labs would be the way to reform the course curriculum to address scientific reasoning, however, this course did not have a hands-on lab section, but it did have a computational lab component. This constraint suggested videos as the medium for an intervention. It was believed that videos of short demonstrations or trial runs of experiments which required students to think about control of variables and proportional mathematical reasoning could still accomplish instruction in some of the science reasoning skills that students were missing in not having a hands-on lab [7-11]. In addition, because students tend to like videos and enjoy new technology in their education, and because many well-made video clips exist on the web which show science in action [9, 10], the researchers hoped that this reform would improve students' attitudes about science and help them perceive the physics that happens all around them as part of their everyday lives.

\section{EXPERIMENTAL METHODOLOGY}

This instructional reform was for a low math general education physics course designed for non-technical, non-science majors at a large public undergraduate institution. The class had between 60 to 80 students per semester; it was taught in a traditional large lecture that met for 75 minutes twice a week. The course had a computer lab component but, as discussed above, no regular hands-on experimental labs. The course used clickers and online homework with an electronic textbook.

Fall semester served as a control semester for the study while spring semester was taught by the same professor in the same fashion except for the addition of this video curriculum, which students completed outside of class in eight sessions each lasting around twenty minutes. Pre- and posttests were used to assess the effects of the course on student attitudes toward science and their scientific reasoning skills.

The CLASS test, or the Colorado Learning Attitudes about Science Survey, was used to assess changes in students' attitudes toward science [6]. The CLASS test utilizes a Likert scale where students rank how much they agree or disagree with a series of 42 statements. These statements often do not have a clear "right" or "wrong" answer, but there are questions that instructors hope students agree with and questions instructors hope they disagree with. For example, a question students hopefully agree with, "I think about the physics I experience in everyday life," and a question they would hopefully disagree with, "Knowledge in physics consists of many disconnected topics."

The Lawson Scientific Reasoning test was used to assess student's abilities to reason scientifically [2]. This test is organized into questions pairs, such that the first question tests student knowledge of a scientific concept and the following question tests the reasoning used to explain the first question's answer. This test assesses science reasoning skills like control of variables, proportional reasoning, correlational reasoning, probabilistic reasoning, and some general science knowledge. 


\section{THE INSTRUCTIONAL MODIFICATION - VIDEOS}

The instructional modification consisted of eight short videos that were added to the existing course material during the spring semester. (Figure 1 summarizes the video topics addressed in each video, the physics taught, and the main features of each video.) The videos were watched during the weekly computational lab time for the course, which is proctored by a teaching assistant. Every video was accompanied by a worksheet that students completed as they watched the video and then submitted for a completion grade.

The structure of each video was similar but each focused on a different physics topic that was relevant to the course material for that week. The basic structure of the videos was as follows: an introduction to that week's topic; discussion of relevant variables that play a role in that physical system; a mathematical derivation and/or experimental demonstration that tests these variables; a summary of the findings on how the variables discussed affect the physical system; a fun clip from YouTube that illustrates the weekly topic with higher production value video. All videos were constructed by the research team. This included filming and editing. The YouTube clips were the exception to this and were edited into the videos but not filmed by the team.

In order to film the introduction and discussion of relevant variables as well as any mathematical explanations, an iPhone was placed on a stand and aimed downward at a piece of paper or notebook. This captured, from above, a hand writing out the definitions, drawing pictures to explain the topic, or mathematical derivations (see Figure 2 for a captured image). Once these film clips were recorded, they were uploaded to the video editing software Camtasia. This software allowed for the clips to spliced together, sped-up or slowed-down, and for a voiceover to be created that explained and discussed the topic. The software allowed the voiceover to be recorded in short clips and to be edited so that mistakes could be removed or recorded over.

Each video also had an accompanying worksheet students completed while watching the video; there were five questions per video on average. The videos would show a slide and have a voiceover asking students to pause the video and answer a specific question on the worksheet before moving on. The worksheet questions varied in style (e.g. multiple choice, free response, or calculation) depending on their purpose. Some of the questions assessed/encouraged students to pay attention to the video, such as, "What mark did the water come up to?" or, "Which pendulum took longer?". Other questions asked students about a targeted concept to test their knowledge and then would answer that question in the video following. For example, the question that follows the top clip shown in Figure 2 is, "Which pendulum should you use to investigate mass's effect on period?" Then just following this, students are told any matched length pair would work, and they are shown the experimental trial of the two long pendulums, i.e. B and C.

For example, the layout of the pendulum video went as
FIG. 1. Video topics and the physics learning objectives.

\begin{tabular}{|c|c|c|c|}
\hline Topic & $\begin{array}{c}\text { Length } \\
\text { (Min) } \\
\& \\
\text { Worksheet } \\
\text { Questions }\end{array}$ & $\begin{array}{l}\text { Weekly Physics Specific } \\
\text { Instructional Objectives }\end{array}$ & Video Clips \\
\hline $\begin{array}{l}\text { Volume of a } \\
\text { Cylinder }\end{array}$ & $\begin{array}{c}5: 34 \\
\& \\
5\end{array}$ & $\begin{array}{l}\text { Height and radius's effect } \\
\text { on cylinder volume. }\end{array}$ & $\begin{array}{l}\text { No extra } \\
\text { videos included } \\
\text { in this week. }\end{array}$ \\
\hline Free Fall & $\begin{array}{c}6: 39 \\
\& \\
3\end{array}$ & $\begin{array}{l}\text { Effect of mass on free } \\
\text { fall time and how air } \\
\text { resistance changes this. }\end{array}$ & $\begin{array}{l}\text { YouTube: BBC } \\
\text { feather and } \\
\text { bowling ball. }\end{array}$ \\
\hline $\begin{array}{l}\text { 2D Motion: } \\
\text { Superposition }\end{array}$ & $\begin{array}{c}5: 26 \\
\& \\
4\end{array}$ & $\begin{array}{l}\text { Horizontal motion is } \\
\text { independent of vertical } \\
\text { motion. Superposition of } \\
\mathrm{x} \text { and y gives actual } \\
\text { motion. }\end{array}$ & $\begin{array}{l}\text { YouTube: } \\
\text { Shoot the } \\
\text { Monkey } \\
\text { Starring Daniel }\end{array}$ \\
\hline Friction & $\begin{array}{c}6: 03 \\
\& \\
8\end{array}$ & $\begin{array}{l}\text { Mass, surface, and surface } \\
\text { area's effect on friction. }\end{array}$ & $\begin{array}{l}\text { You Tube: } \\
\text { Life w/out } \\
\text { friction. }\end{array}$ \\
\hline $\begin{array}{c}\text { Energy } \\
\text { Conservation }\end{array}$ & $\begin{array}{c}7: 32 \\
\& \\
6\end{array}$ & $\begin{array}{l}\text { Different forms of energy } \\
\text { and how the variables } \\
\text { affect the energy. } \\
\text { Conservation of energy. }\end{array}$ & $\begin{array}{l}\text { No extra } \\
\text { videos included } \\
\text { in this week. }\end{array}$ \\
\hline $\begin{array}{l}\text { Period of a } \\
\text { Pendulum }\end{array}$ & $\begin{array}{l}8: 31 \\
\& \\
6\end{array}$ & $\begin{array}{l}\text { Mass and length's effect } \\
\text { on period. }\end{array}$ & $\begin{array}{c}\text { YouTube: } \\
\text { Pendulum } \\
\text { Waves Starring } \\
\text { Allen }\end{array}$ \\
\hline Waves & $\begin{array}{c}6: 42 \\
\& \\
3\end{array}$ & $\begin{array}{l}\text { Definitions and relations } \\
\text { among variables that } \\
\text { describe a wave. }\end{array}$ & $\begin{array}{l}\text { YouTube: } \\
\text { Ruben's Tube } \\
\text { with Music }\end{array}$ \\
\hline Probability & $\begin{array}{l}8: 50 \\
\& \\
8\end{array}$ & $\begin{array}{l}\text { Probability is in terms of } \\
\text { a counting of possible } \\
\text { states. How to use } \\
\text { probability with repeated } \\
\text { events. }\end{array}$ & $\begin{array}{l}\text { YouTube: } \\
\text { Ed.ted.com } \\
\text { Castaway } \\
\text { probability of } \\
\text { dice rolling }\end{array}$ \\
\hline
\end{tabular}

follows. Period of a simple pendulum is defined and the variables mass and length are suggested as possible variables that might affect the period. The three possible options for how mass and length could affect the period are outlined, i.e. mass does affect the period would mean increasing mass would give larger (or smaller) period and mass does not affect the period would mean increasing mass does not change the period. Students are asked to make predictions of the relationships. Next, the top image, in Figure 2, is drawn for students and they are asked worksheets questions addressing which pendulums would be useful to test for mass and length's effect on period and addressing what should be observed if a certain prediction is correct. (E.g. If length does affect the period of the pendulum what should you observe?) Then, students were shown a set of controlled experiments and the voice over discusses what they are seeing and the findings. Finally, a YouTube clip titled "Pendulum Waves starring Allen" is shown which displays the "beats" that 15 pendulum bobs of just the right length go through. Other videos are of course different, but all videos focus on discovering what variables affect a property of the system, control of variables while experimenting, and the correct reasoning from an observation. 


\section{A. Brief description of the main features of each video}

1. Volume of a Cylinder: Uses water and test tubes to show the linear and nonlinear relationships of volume to height and radius respectively. Then, the expression $V=\pi r^{2} h$ is derived.

2. Free Fall: The three options for mass's effect on fall time are discussed. Slow motion video of the experiment is shown. Discussion of Newton's second law $F=m a$ and $F n e t=m g$ in free fall explains that they fall at the same rate because they have the same acceleration. Discussion of Fnet $\neq m g$ when air resistance is present is also addressed.

3. 2D Motion: Video demonstration of balls dropped and rolled off a table hitting at the same time is shown. Discussion and mathematical derivation of $t=\sqrt{2 h / g}$ for both is made and motion maps are used to illustrate the paths.

4. Friction: Reasoning and control of variables are emphasized. A series of blocks are pulled on a table the spring readout shows the effect of each variable. Conclusions and reasoning are discussed.

5. Energy Conservation: Presentation of the expressions for kinetic and potential energy and a mathematical derivation of $h \propto v^{2}$ as the relationship of speed to height decrease on a frictionless incline if energy is conserved. Also, the independence of speed to mass of the cart is considered. Then, these quantities are tested experimentally with photogates and a track to show that the model of energy conservation is not disproven. Scientific validation and proof are discussed.

6. Period of a Pendulum: The worksheet requires students to plan the experiment to test each variable (mass and length's) effect on period and a discussion is made of the observations that could occur and the correct interpretations of these observations. This video strongly emphasizes control of variables. (This video is already described in greater detail previously in this paper.)

7. Waves: Discussion is made of the variables that describe a wave (wave speed, length, frequency, amplitude) and the relationships between these variables are created from these definitions. A wave simulation of a ripple tank is used to visually investigate the effect of changing frequency or wavelength.

8. Probability: Different numbers of nickels, dimes, pennies, quarters are used to illustrate probability of events as counting of states. Conditional probabilities are addressed too via a table of options for heads and tails.
FIG. 2. A screen capture showing the style of the video clips. Above is an example of a control of variables discussion and below is the experiment performed.

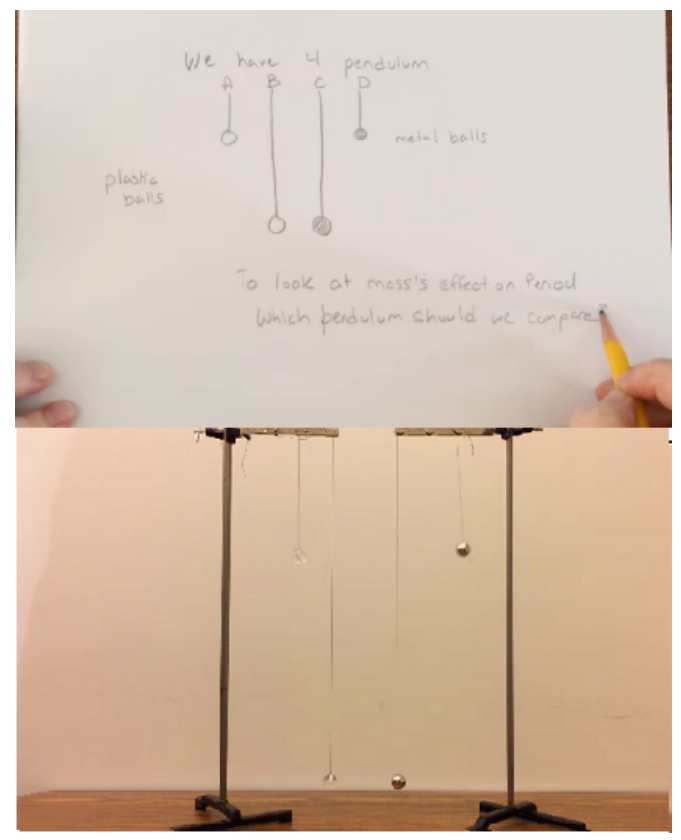

\section{ANALYSIS OF FINDINGS}

Analysis of the CLASS scores can be complicated since there are no correct answers and because on some questions a low Likert value is desirable and other questions a higher value is the goal. CLASS designers usually analyze these questions together in an expert vs. novice coding; however, since pre-post changes were observed to be different for agree and disagree items, these items are analyzed separately here. In addition, the pre-post data was analyzed in two ways.

If the pretest response and posttest response were equal students were given a score of zero. If the posttest response was a higher number than the pretest response, the student was assigned $\mathrm{a}+1$ on that question and correspondingly if it was a lower value $\mathrm{a}-1$. This means that if a student moved from 1 to 5 they were given the same score as a 3 to 4 move so some of the detail of the data is lost but this allows for a simple comparison to be made. (This is called coding 1 and the results of this analysis are shown in Table I.)

The CLASS designers indicate that there are 18 of the 42 questions that a person with a positive attitude toward science would agree with, 18 questions they would disagree with and 6 neutral questions. Using the above scoring method, agree questions showed shifts (pre to post) away from agree for the fall control semester of $20 \%$ but a shift away from agree of only $6 \%$ for the experimental spring semester. On the disagree questions, fall semester showed a shift away from disagree of $14 \%$ and a shift away of $11 \%$ for spring. A T-test comparison of fall and spring shows that the agree questions are significantly different $(F=6.970, p<0.01$, effect size 
TABLE I. Changes in CLASS attitudes over the semester. In both semesters students' attitudes negatively changed but in the experimental semester this change was less pronounced. Coding 1 and 2 are different analysis methods for the Likert pre to Post changes.

\begin{tabular}{ccc}
\hline \hline Coding 1 & Agree Shifts & Disagree Shifts \\
Fall - Control $(\mathrm{N}=93)$ & $-20 \%$ & $-14 \%$ \\
Spring - Experimental $(\mathrm{N}=50)$ & $-6 \%$ & $-11 \%$ \\
\hline Coding 2 & Agree Shifts & Disagree Shifts \\
Fall - Control $(\mathrm{N}=93)$ & $-35 \%$ & $-25 \%$ \\
Spring - Experimental $(\mathrm{N}=50)$ & $-14 \%$ & $-18 \%$ \\
\hline \hline
\end{tabular}

of 0.5) but the disagree questions are not significantly different $(F=0.44, p=0.5)$. Based on these results this two hour video intervention improved students' science attitudes as measured by the agree CLASS questions.

The data was also coded based on how far students shifted. For example, when going from a 5 to a 2 students were assigned a value of -3 if they were supposed to agree with that question and $\mathrm{a}+3$ if this was a disagree question. This coding allowed for the degree to which students changed their opinion on each item to be measured. Coding 2 shows that when the largeness of shift is considered similar averages to those discussed above are seen but the results are exacerbated. On agree questions, students shifted away from agree by $35 \%$ in fall semester but only by $14 \%$ in spring. On disagree questions, students shifted away from disagree by $25 \%$ in fall and $18 \%$ in spring. As for coding 1, agree questions are significantly different $(F=5.124, p=0.025)$, but the disagree are not.

To look at science reasoning, Lawson posttest scores were analyzed (see Table II). Spring semester students scored $4 \%$ better on the Lawson test as a whole than in fall semester. This is not a significant difference given the number of students in the study $(F=1.826, p=0.179)$. However, the question data showed two question pairs that did not match the other patterns of responses seen for spring semester. Upon inspection, it was observed that both of these question pairs were over material that was not covered in the video interventions. When these four questions are removed from the set of twenty-four questions, and a post hoc analysis is run on the data, students in spring semester did $7.2 \%$ better overall, which is significant ( $F=4.507, p=0.036$, effect size 0.4 ).

TABLE II. Lawson posttest scores and standard deviations

\begin{tabular}{ccc}
\hline \hline Semester & Whole Test & Covered Topics \\
\hline Fall - Control $(\mathrm{N}=93)$ & $53.7 \% \pm 18.1 \%$ & $57.9 \% \pm 19.4 \%$ \\
Spring - Experimental $(\mathrm{N}=50)$ & $58 \% \pm 17.4 \%$ & $65.1 \% \pm 19.4 \%$ \\
\hline \hline
\end{tabular}

\section{CONCLUSIONS AND IMPLICATIONS}

This study investigated the impact of eight new instructional videos on students' scientific reasoning skills and attitudes toward science. The Lawson's test and the CLASS test were both used to assess this project, testing scientific reasoning skills and attitudes toward science respectively. Results show that this video intervention, which took students about two hours in total to complete over the course of the semester, significantly improved students science reasoning skills and their attitudes towards science. Students scored $7 \%$ better on the Lawson's science reasoning test in the semester videos were used. Also, while the course did still show a negative shift in student attitudes pre to post, which is common for introductory physics courses [6], this shift was less pronounced in the semester with the video intervention.

Future research with these videos is planned for fall 2017 to test if the effects observed are fall vs. spring population related. Also, most of the videos had some small error or piece that could have been fixed or improved. For example, a wave graph is shown in time and wavelength and period are both discussed on this graph as an oscillation or another video has a fair amount of sniffing in the voiceover. These can be cleaned up for the fall and/or future implementations of these videos.

\section{ACKNOWLEDGMENTS}

Thanks to Rebecca Lindell for her writing workshop and to White Boards USA who provided the travel money for the presentation of this work at AAPT and PERC.
[1] Next generation science standards, http://www.nextgenscience.org/ (12/2/2016).

[2] A. E. Lawson, Journal of Research in Teaching Science 15 (1), 11-24 (1978).

[3] L. Bao, C. Tianfan, K. Koenig, K. Fang, J. Han, J. Wang, Q. Liu, L. Ding, L. Cui, Y. Luo, Y. Wang, L. Li, N. Wu, Science, 323(5914), 586-587, (2009).

[4] A. Boudreaux, P.S. Shaffer, P.R.L. Heron, and L.C. McDermott, Am. J. Phys., 76 (2) 163-170 (2008).

[5] R. J. Rosenblatt and J. Perrone PERC Proceedings, (2016).

[6] W. Adams, K. Perkins, N. Podolefsky, et al., Phys Rev. ST-PER,
2, 101010 (2006).

[7] N. S. Podolefsky and N. D. Finkelstein, Phys. Teach. 44, 338342 (2006).

[8] R. Sokoloff and R. K. Thornton, Phys. Teach. 35, 340-347 (1997).

[9] H. R. Sadaghiani, PRST-PER, 8, 010103 (2012).

[10] R. Beichner, Am. J. Phys., 64 (10), 1272-1277 (1996).

[11] N. Finkelstein, W. Adams, C. Keller, P. Kohl, K. Perkins, N. Podolefsky, S. Reid, S. LeMaster, PRST-PER, 1, 010103, (2005). 